\title{
Editorial: Discontinuities in learning with technologies
}

Sue Greener Brighton Business School, M103 Mithras House, Brighton, UK s.l.greener@brighton.ac.uk

Attending conferences in different parts of the world on learning with technologies is a sobering experience. It is easy to imagine this globally connected world as a single space, a space with no frontiers, no boundaries, everything accessible and understood. We know, of course, that this is not the case. That everywhere there are frontiers and discontinuities and barriers to be surmounted.

The first that come to mind are geographical frontiers. Academics are privileged to be able to cross countries in search of research partnerships and cross-sectional comparative data. As always when meeting new people and making an effort to communicate, we are struck by our similarities. We may face as teachers the same issues with students, timetables, resources and learning and teaching concerns. Yet deeper dialogue starts to highlight the gulfs existing between countries. The compulsory schooling differences, what is expected of learning habits and memory in particular, the extent or lack of questioning and challenging knowledge. Post-compulsory educators are faced with increasing difficulties as wider, more diverse populations are demanding a higher or further education, yet often lacking the prerequisites of knowledge and learning habit for that education to make sense in their lives. Learning technologies can come to the rescue here, offering introductory outlines and scaffolding with interactive tests, if chosen wisely, and offering this through a mix of media which are comfortable for younger learners.

But discontinuities are not just between countries in a geographical sense, local, regional and national education policies can sometimes prioritize targets which may have less to do with learning and more to do with funding, in particular what is available through commercial channels and funding agencies. National educational drivers for emerging economies relate to economic growth, inclusive and sustainable development; any focus on quality of education is likely to focus on measurable qualifications achieved and skills acquired, which feed directly into widening participation and economic contribution. While these are laudable objects in themselves, they can easily distort educational development as outcomes are prioritized over process and standardized outcomes in particular can crowd out creative and autonomous personal development.

There are also discontinuities in terms of social behaviour. Web 2.0 encourages interaction: learners' contributions to each other, not just those of the teacher. But in many parts of the world there is a strong reluctance to challenge and question; a need to find and accept authority in the published word. There is also an understandable human reticence, which can constrain learners and teachers trying to make their voices heard via the Web. Any teacher who has done some simple experiments with discussion or message boards will recognize this. Sometimes this reticence is cultural, stronger than individual shyness, communities can find it difficult to venture into public space, seeing the status of learner as lesser than that of teacher. These are considerable barriers for teachers and trainers trying 
to develop learning through blogs and wikis and other self-publication, even collaborative games, online.

Then of course there are still major discontinuities in access to technology around the world. This may be to do with availability of energy (for example load shedding of electrical power by utilities), or money and the latest mobile devices. It may also have to do with political constraints of freedom of information, or conditions of war which can cause media access to be blocked.

In this issue we have a paper on using games in learning: Hummel et al. who write about an online game concerning classroom dilemmas in teacher education, and we offer a discussion of academic self-regulation in hyper-media environments (Gorrissen et al.) plus a paper on pedagogical structure and design in computational model-based learning (Jacobsen, Kim, Pathak and Zhang). In some cases, specific intermediaries are useful in learning development: in this issue $\mathrm{Wu}$, Wang and Chen discuss a locally built assistant robot to help primary school age learners with English as a Foreign Language, and Wu, Wu, Kuo and Hsu discuss a computer-based modelling tool for scientific practice in the atmospheric sciences. Technology continues to provide active environments for learning in three papers: integrating Moodle and Office as an elearning platform is discussed by Palumbo and Verga, and both Gavish et al. and Lin, Chen and Chang discuss different approaches involving augmented reality for interactive learning both in educational and work environments. Although interactive whiteboards have been discussed over a number of years, there is still reluctance in some institutions to use them as more than a static resource: Wong, Teo and Goh develop a model to understand better student teachers' uptake of this tool. Finally James Life, from Korea, gives a perspective on the drive to achieve academic standing and social position in Higher Education.

These papers demonstrate some of the pioneering practices in interactive learning technologies, they deal with what is possible and what could be possible. For the practitioners who read this issue, rest assured that all these discussions of exciting developments could be in your learning environment one day; though for now, we have to recognize the gulfs which can exist between research papers and actual educational practice. All the practical discontinuities discussed here will not halt the development of Web 2.0 and Web 3.0 interactions globally, but they do make teachers stop and think about the innovative learning activities they may hope to practise.

Sue Greener, Co-Editor, Interactive Learning Environments 